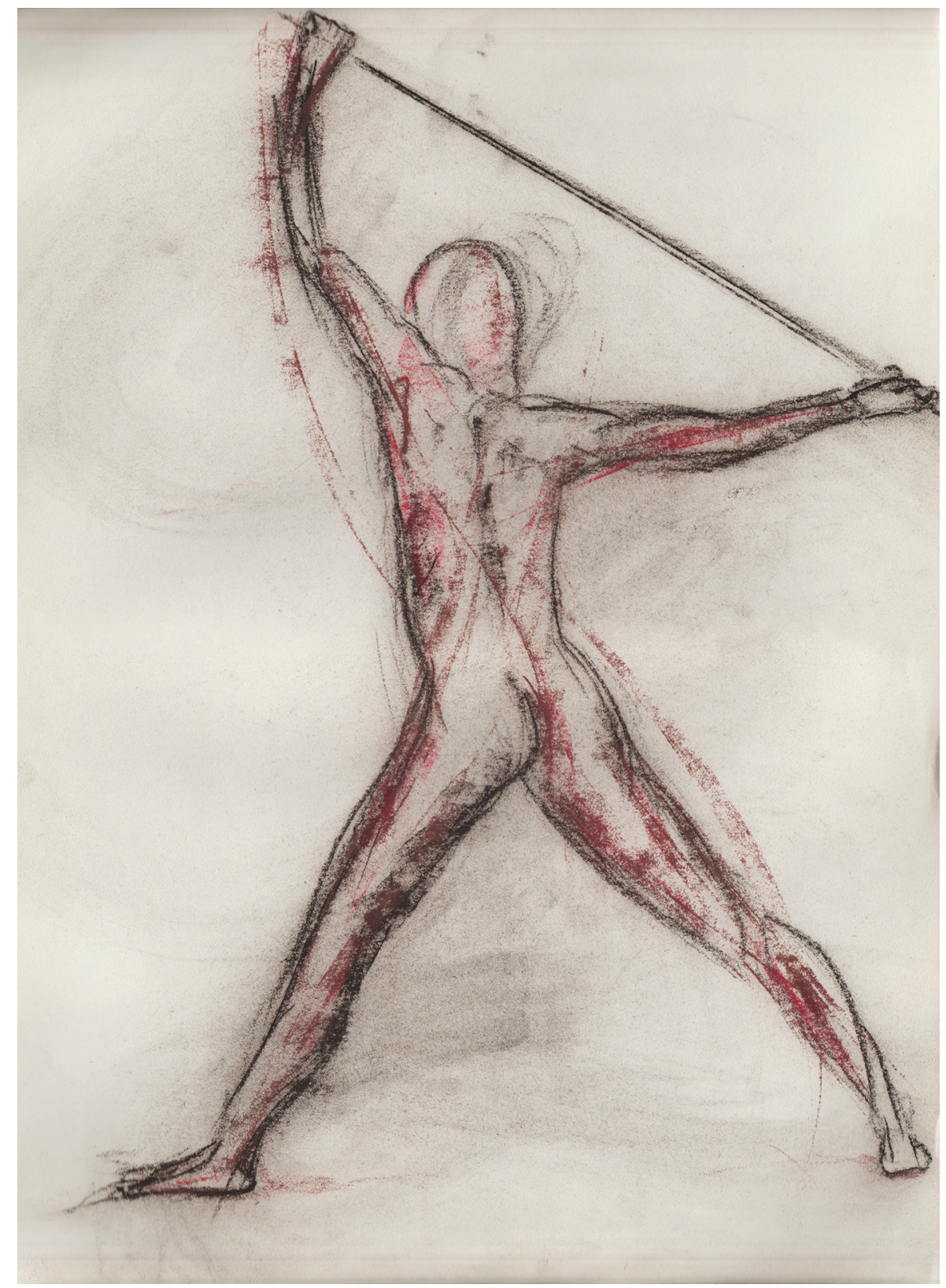


AUToR: Guillermo Calviño 


\title{
Unha casa para Lupe Gómez: espazo afecto e memoria en Camuflaxe (2017)
}

\author{
Gisella Costas \\ Universidade de Santiago de Compostela \\ https://orcid.org/0000-0002-9005-9289
}

[Recibido, 17 decembro 2020; aceptado, 6 maio 2021]

[Costas, G. (2021). Unha casa para Lupe Gómez: espazo, afecto e memoria en Camuflaxe (2017). Boletín Galego de Literatura, 58, "Notas", 5-22]

DOl http://dx.doi.org/10.15304/bgl.58.7291

RESUMO Camuflaxe, publicado e recoñecido en 2017 co Premio da Crítica Española, é un dos últimos libros de poemas escrito pola autora galega Lupe Gómez. Nas súas páxinas, que abordan temas tan íntimos como a infancia, a casa familiar ou os lazos materno-filiais, está latente o compromiso dunha conciencia literaria que busca representar os custos da perda e da destrución tanto da terra como dos modos de vida vencellados ao rural galego. Con este propósito, a autora artella un poemario no que se cruzan os afectos e a memoria, tanto colectiva como privada, no espazo da periferia galega, elementos que serán analizados a fin de comprender a maneira na que se relacionan e constrúen o ambiente que envolve os poemas. En definitiva, Lupe Gómez sérvese da palabra poética como lugar de memoria para denunciar unha realidade marcada pola inxustiza social dando lugar, deste xeito, a un discurso poético de resistencia.

Palavras CHave Espazo; afecto; memoria; Camuflaxe; Lupe Gómez.

ABSTRACT Camuflaxe, published and recognized in 2017 with the Spanish Critics Award, is one of the last books of poems written by the Galician author Lupe Gómez. In its pages, which deal with such intimate issues as childhood, the family home or mother-child ties, there is an underlying commitment of a literary consciousness that seeks to represent the costs of the loss and destruction of both the land and the ways of life connected to Galician countryside. For this purpose, the author articulates a book of poems in which affects and memory, both collective and private, intersect in the space of Galician periphery. Those elements will be analyzed in order to understand the way in which they relate to each other and construct the environment that surrounds the poems. In conclusion, Lupe Gómez uses the poetic word as a place of memory so as to denounce a reality that is marked by social injustice and, thus, gives rise to a poetic discourse of resistance. Kerwords Space; affect; memory; Camuflaxe; Lupe Gómez.

\section{Introdución}

O campo poético galego vén atendendo, dende hai uns anos, un espertar da conciencia literaria acerca dos custos da perda e destrución da terra 
e dos modos de vida vencellados ás zonas máis rurais. Estes son propios dunha Galicia á que os seus habitantes aínda se manteñen suxeitos por lazos fortes, profundos e complexos que resisten ante a promesa utópica do progreso. Os autores, e especialmente as autoras deste momento, abordan esta perda coa intención de empregar a palabra poética a modo de lugar de memoria ${ }^{1}$ que recolla unha crítica radical cara a unha realidade material que se presenta atravesada por profundas inxustizas sociais contra a terra, a vida e a lingua de Galicia. Neste sentido, a poeta e narradora Lupe Gómez sitúase aquí como unha das autoras máis comprometidas á hora de tratar os procesos de perda como unha prioridade na súa obra; demóstrano así libros tan recoñecidos pola crítica literaria como Fisteus era un mundo (2001), $O$ útero dos cabalos (2005) ou, dun xeito especial, un dos seus últimos libros de poemas no que se enfocará este ensaio, Camuflaxe (2017).

De acordo con isto, o obxectivo desta análise será achegarnos ao poemario de Lupe Gómez coa intención de atender á relación entre espazo, memoria e afecto á hora de construír o marco espacial e o ambiente que envolven os poemas, entendendo que ambos os sitúan nun lugar a medio camiño entre o pasado e o presente. Isto é, a poeta atende, especialmente, o lugar no que se dispón e sitúa o libro partindo dunha perspectiva que dá conta da súa liminalidade a través dunha atención particular á noción de espazo percibido, así como ao símbolo da casa interpretado polo filósofo francés Gaston Bachelard (1957). Desta maneira, pretendemos comprender a centralidade dos afectos e da memoria na súa escrita, mais tamén o papel que xoga a ecoloxía no seu discurso poético.

\section{Os usos políticos da palabra poética}

Lupe Gómez comeza a publicar a finais do século pasado, na década dos anos 90, co poemario Pornografía (1995), autoeditado durante a coñecida eclosión de voces femininas na poesía galega contemporánea que

\footnotetext{
O termo e concepto lugar de memoria parte do historiador francés Pierre Nora, vinculado á denominada nova historia, e, concretamente, dos seus estudos relativos a cuestións da identidade e da memoria. Este concepto foi empregado para darlle nome á súa obra Lieux de mémoire dividida en tres tomos: La République, La Nation e Les France, editados entre 1984 e 1992. Neles o investigador realiza un inventario dos lugares e dos obxectos nos que atopa de maneira encarnada a memoria nacional do seu país.
} 
desembocou na chamada xeración dos 90. Dita eclosión do discurso poético das mulleres foi recoñecida por abrir novos camiños para a literatura galega en relación con cuestións relativas á identidade ou ao xénero, mais tamén pola preocupación que mostraron polos emerxentes movementos sociais entre os que se incluía o ecoloxismo. Vinte anos máis tarde, Camuflaxe aparece no panorama literario galego como unha revelación íntima "sobre a extinción cultural e física dunha comunidade", tal e como reza a súa capa, co fin de construír, ante todo, unha imaxe de resistencia.

Fronte á incapacidade transgresora dos mitos nacionais, por motivo da súa tendencia ao esencialismo, increméntase exponencialmente, nesta época, o número de autores que se servirán da palabra poética co obxectivo de converter a pura narración estética nun marco sociolóxico de acción que sirva a unha fin transformadora. A crítica literaria María Xesús Nogueira analiza este uso crítico do nacionalismo na obra das poetas Lupe Gómez e Chus Pato nas páxinas do seu artigo "Identidade, nación e compromiso na poesía galega do novo século escrita por mulleres" mediante a noción de usurpación:

O discurso sobre a nación-identidade usurpada contextualízase ademais nunha constante denuncia da alienación derivada da historia e da propia evolución do sistema económico capitalista, cuxa repercusión se percibe nas transformacións dos modos de explotación de noso e na propia lingua, representada como unha identidade perdida e en conflito. (2011, p. 114)

Nesta liña, Chus Pato escribía así no seu poemario m-talá (2000) sobre o que existe de conflitivo na relación entre o nacionalismo e a identidade: “o nacionalismo é unha cuestión de identidade, róubanche a identidade porque esa identidade xa non pode ser, e logo sofres toda a vida polo roubo [...]. A reconstrucción desa identidade, a súa imposible reconstrucción, son a historia da nación, a historia do poema” (p. 48).

É por esta razón que as poetas contemporáneas afástanse da tradicional poesía paisaxística, que fora empregada polos nacionalismos durante o século XIX, deixando de representar, en consecuencia, as estampas do mundo rural como un espazo idealizado no que os suxeitos poden atopar unha identidade colectiva. Pola contra, estas presentan unha imaxe desmitificada destes espazos e, da mesma maneira, dos modos de vida propios deles co fin de crear unha defensa lingüística, antropolóxica e mesmo te- 
rritorial. A partires dos anos oitenta, xorden movementos sociais en contra da crecente privatización e explotación da terra xerando, así, na literatura un contra-discurso que apunta cara a unha volta ao natural por medio dunha lingua territorializada e desmitificadora.

A teórica María do Cebreiro Rábade (2010) destaca o slogan "a nosa terra é nosa" contra Fenosa como claro exemplo dun discurso de defensa da terra nesta liña. Sen dúbida, este lémbranos aos versos da autora que xuran “os nosos montes nunca serán paisaxes” (Gómez, 2017, p. 80), sentenzas nas que subxace unha resistencia ecoloxista e política fronte á explotación e imposición dos modelos estranxeiros. No caso que nos ocupa, os seus poemas recollen un testemuño do pasado que non se reduce a un acto derivado da nostalxia, senón que escribe coa intención de amosar unha alternativa para o futuro a través da reconciliación co pasado ferido. Esta alternativa estará baseada nunha reformulación do vínculo entre a terra e os seus habitantes e, aínda máis, entre a terra autóctona e a man estranxeira que a explota.

O mundo rural preséntase no poemario de Lupe Gómez como un referente para a representación identitaria, unha representación que fala dunha "nación morta", citando as palabras de $O$ útero dos cabalos (2005), é dicir, dunha nación que actualmente permanece deshabitada e triste e na que se sitúa o símbolo da casa da infancia. Deste modo, a poeta trae ante o lector unha visión crítica que expón o proceso de usurpación territorial, por parte das forzas políticas capitalistas, desencadeado polo desafiuzamento deste espazo periférico e subalterno ${ }^{2}$ que foi, durante décadas, invisibilizado e marxinado en todas as súas dimensións. Neste sentido, o estilo de vida comunitario propio dos habitantes do territorio rural segregado e as súas correspondentes estruturas ideolóxicas, sociais e emocionais eran completamente incompatíbeis co modelo capitalista imperante baseado

2 Subalterno é un termo destacado dentro dos estudos poscoloniais que foi proposto polo marxista italiano Antonio Gramsci nos seus Cadernos do cárcere (1981-2000), escritos entre 1929 e 1935, e foi acoutado, posteriormente, pola pensadora da India Gayatri Spivak. En consecuencia, este concepto pasaría a apuntar os suxeitos excluídos, desprazados e alterizados polos discursos de poder e os que, ademais, se lles ten negado a súa voz dentro do espazo político. A pesar disto, a noción de subalternidade implica unha posición e non unha identidade, o que implica a permanente existencia dunha posibilidade para o subalterno de reverter a súa posición como marxinado dentro do marco do conxunto social, pois entendemos que ten que ver cunha condición e non coa súa propia natureza. 
nos ideais da privatización, o individualismo e a razón, polo que dende o poder da capital fórmase unha beteroimaxe $e^{3}$ da sociedade galega representada como supersticiosa, folclórica e primitiva, definindo así o conxunto do territorio galego como un lugar ligado á pobreza, á ignorancia e a unha natureza salvaxe. En consecuencia, a poeta relata desta maneira o silencio que cobre a terra da súa nai:

Non tiñas idioma.

A Historia cortou cun coitelo interior

a beleza dos teus beizos.

O teu mundo non existía nos mapas.

As túas entrañas eran totalmente secundarias / invisibles.

(Gómez, 2017, p. 37)

O seu libro de poemas posiciónase, polo tanto, como un acto de resistencia, no seu sentido máis espacial, isto é, entendido como unha demostración de lealdade cara ó lugar atravesada dun xeito visceral polo enraizamento e o sentido de pertenza. Neste sentido, a defensa dese espazo supón, así mesmo, a defensa do suxeito político que o habita, é dicir, daquel suxeito que permanece ou que "ten de maneira reiterada", se atendemos á etimoloxía do verbo habitare, creando así lugar no espazo.

\section{A representación literaria do mundo natural}

Por outra banda, en Camuflaxe, a poeta preséntanos unha perspectiva non burguesa da natureza, é dicir, allea ao tópico latino do locus amoenus, xa que non é bucólica nin tampouco semella cousificada, pois a súa verdadeira intención é a de desmitificar o mundo rural e, á vez, deconstruír

3 O concepto de heteroimaxe pertence ao campo do saber teórico da imagoloxía. Entendemos por imagoloxía o estudo das imaxes, prexuízos, estereotipos e opinións que unha comunidade verte sobre outra. No ámbito da teoría literaria, estas imaxes presentes nos textos literarios son analizadas co fin de descubrir os valores ideolóxicos e agochados nelas, que serven como representación do pensamento dunha comunidade e que motivan, así mesmo, a escritura de obras. De acordo con isto, a imagoloxía estuda o xeito no que unha comunidade, cultura ou nación se define ou é definida en oposición a outras. Dentro desta subdisciplina explóranse os conceptos de autoimaxe e heteroimaxe; por unha banda, a autoimaxe é aquela imaxe dunha comunidade sobre ela mesma e, por outra, a heteroimaxe refire a imaxe que unha comunidade crea doutra a partir dos seus propios ideais e pensamentos, agochando, en moitas ocasións, unha cuestión política e ideolóxica. 
esa heteroimaxe estranxeira baseada na idea da aldea atrasada, inmóbil e pobre. De igual xeito, esta aparece a miúdo conxugada cunha misteriosa e perigosa beleza, propia da estética do Romanticismo, que atrae o estranxeiro e a idealiza. Fronte a isto, a poeta amosa unha visión crúa do espazo e da vida que o compón, ademais, por medio dunha ollada atenta á cuestión de xénero en relación coa posición que as mulleres adquiren nestes ambientes, pois, tal e como esta afirma, "as mulleres na aldea non soñan” (Gómez, 2017, p. 23).

$\mathrm{Na}$ liña do que temos exposto, a partires do pensamento do teórico marxista Raymond Williams (2001), podemos soster que unha paisaxe é, ante todo, un xeito de ollar construído historicamente ou, en palabras de Germán Labrador (2016, p. 257): “un sistema combinado de modos de mirar, y de hacer ver, en cuyo interior se negocian alianzas y enemistades político-culturales relativas al dominio tecnológico, económico y militar de un territorio dado".

Por conseguinte, as imaxes descritivas da paisaxe conteñen sempre unha dimensión histórica, tal e como apuntou Raymond Williams, xa que recollen a acción da man humana sobre ela coma se esta fose un palimpsesto. No caso concreto de Galicia, as tallas e a apropiación das terras e dos bens comunais das aldeas a finais do século XIX por parte do Estado supuxeron a fundación violenta dun novo modelo socio-económico capitalista. A concepción da paisaxe como construción cultural estetizada do natural e supeditada a unha perspectiva humana emerxe xunto co inicio da explotación natural a grande escala (López, 2012, p. 51). Deste xeito, a natureza comeza a ser explotada respondendo a unha concepción mecanicista da mesma que a entendía como algo inerte e á disposición dos seres humanos para servirse dela no seu propio e único beneficio.

En relación con este cambio, dado pola transición cara a un modelo socio-económico sometido ao mercado, a arte e o discurso literario adquiren unha función compensatoria cara a esa perda mediante unha recuperación simbólica da natureza devastada (López, 2008, p. 68). Neste caso, a paisaxe pode cumprir unha función reparadora e social á vez que abre unha fenda entre o individual e o colectivo envolta nunha profunda tensión. Achegándonos aos textos literarios somos quen de, en consecuencia, atender o cambio contextual dos espazos, pois, tal e como estudou o antropólogo 
e investigador intercultural Edward T. Hall no capítulo "El lenguaje del espacio" do seu libro La dimensión oculta (1966), podemos ver e interpretar nos textos, ao igual que nas súas estruturas, de que xeito se modifican os ambientes e o uso dos sentidos, demostrando que estes últimos varían de maneira histórica no espazo e no tempo.

Lupe Gómez realiza, neste sentido, unha tentativa de representación da complexidade do mundo natural así como da fraxilidade das relacións entre natureza e humanidade, recoñecéndolle neste eido á man humana un papel indisociable dos procesos de creación e destrución do medio. A autora proxecta sobre a natureza e a comunidade rural galega unha conciencia das dinámicas violentas do mundo que a posiciona, en termos de Harry Heft e Jauad El-Kharraz Nazar (2000), como unha "observadora activa e comprometida". Desta maneira, a poeta encara os efectos perniciosos do discurso capitalista e a súa concepción do mundo rural como unha fonte de recursos a ser explotada polo novo modelo industrial. Amosa, ademais, os seus efectos non só sobre a propia terra senón igualmente sobre a totalidade da comunidade, incidindo, deste modo, no feito da súa indisociabilidade.

\section{Acerca da relación entre espazo, afecto e percepción}

Seguindo o pensamento de Raymond Williams, Germán Labrador (2016, p. 259) afirma que as representacións paisaxísticas deben ser lidas historicamente en relación coas estruturas de sentimento ${ }^{4}$ colectivas así como coas comunidades emocionais ${ }^{5}$, en termos afectivos, que remiten á des-

4 A noción estrutura de sentimento foi proposta polo teórico marxista e materialista Raymond Williams no seu libro Marxism and Literature (1977). Esta permite comprender o mundo afectivo no marco da socioloxía como histórica, social e culturalmente mediados, pois implica a idea de que cada período ten os seus códigos emocionais que mudan co tempo e dan forma non só á súa expresión, senón tamén ás propias emocións. Estas estruturas de sentimento correspóndense cun modo de vida concreto derivado, ademais, dun determinado xeito de vivir e de pensar que constitúen o posicionamento colectivo dunha comunidade cara ó mundo cando comparten contexto e uns condicionamentos sociais e materiais semellantes. En consecuencia, as estruturas predispoñen os corpos exercendo unha presión que delimita as experiencias e os os modos de vida e que establece o xeito no que se relacionan e valoran os suxeitos e obxectos (pp. 131-132).

5 Barbara H. Rosenwein (2006) acuña o termo comunidade emocional a finais dos anos noventa do século pasado no seu libro Emotional Communities in the Early Middle Ages. Este defínese como aquel grupo que comparte un conxunto de normas ou códigos acerca das 
posesión dada polo progresivo dominio do capital sobre os corpos e o territorio, configurando así a paisaxe como un lugar de memoria. Nesta liña, Edward T. Hall serviuse do neoloxismo proxemia para estudar a distancia agochada entre as persoas e os espazos, é dicir, a dimensión oculta na que se producen as relacións e afectos. Noutras palabras, o termo permite analizar a maneira na que as persoas perciben o espazo, o ocupan e se apropian del atendendo ás interaccións sensoriais e imperceptíbeis xeradas entre ambos. De acordo con isto, o territorio constitúese, para el, como unha "prolongación do organismo" marcado por signos visuais, verbais e olfactivos.

Os espazos ou lugares -seguindo a distinción de Yi-Fu Tuan (1997) defínense e modifícanse a través das súas redes de relacións de veciñanza así como dos afectos xerados a partires da rozadura que o filósofo neerlandés Baruch Spinoza denominou encontro na súa Ética (1677). Foi na lectura que Gilles Deleuze (2009) realiza desta teoría de Spinoza, onde o autor afirmou que os afectos non se dan no propio suxeito, senón que xorden do roce ou do contacto entre este e o mundo exterior, isto é, nos encontros entre dous corpos ou entre un corpo e outro elemento, podendo ser este un obxecto ou o propio espazo que o rodea. Podemos entender, por conseguinte, que os espazos, e especialmente os lugares, non son asépticos, tal e como pensaba Schopenhauer, pois están profundamente condicionados pola nosa vida así como pola nosa experiencia persoal pasada e presente.

Os estudos de Edward Casey (2000) afondan no papel da relación entre corpo e espazo durante os procesos de xeración e transmisión de afectos, ó igual que nos de produción de lugar. Este afirma que o corpo é un elemento central á hora de estudar a experiencia espacial, pois o lugar ten sempre unha dimensión corporal que produce unha relación dinámica entre o

emocións así como unha valoración común das mesmas que lle permite pensar o seu papel na experiencia vital para alén dos límites marcados pola sociedade moderna.

6 Segundo a distinción que realiza Yi-Fu Tuan (1997) entre as nocións de espazo e lugar, por unha banda, o espazo é entendido como algo abstracto e externo que opera como colector das cousas, mentres que, por outra banda, o termo lugar implica unha dimensión experiencial e afectiva dada por unha acción humana que conecta un espazo concreto co plano histórico e identitario, creando, desta maneira, lugar no espazo. En consecuencia, o termo lugar ostenta un significado e unha singularidade que o distinguen do concepto abstracto de espazo, é dicir, a súa caracterización depende da percepción e a diferenciación dado que, individualmente, o lugar adquire esa condición grazas á experiencia afectiva que crea e permite unha vinculación ou conexión emocional entre un espazo concreto e unha persoa. 
corpo e a paisaxe do seu redor. Así mesmo, certas prácticas sociais contan coa capacidade de crear lugar a través das chamadas forzas afectivas, xa que estas lles confiren un novo sentido de identidade e privacidade que, igualmente, implica unha multiplicación das oportunidades que estes lugares ofrecen ao grupo social, converténdose, polo tanto, nun lugar moito máis dinámico e flexible fronte á organización espacial imposta.

En diálogo coa teoría de Brian Massumi (2002), podemos dicir que os afectos non residen, en definitiva, nin nun corpo en particular nin, neste caso, nun lugar concreto, senón que son autónomos polo feito de nacer da interacción dinámica e relacional entre os corpos ou entre corpos e lugares. A produción de lugar consiste, por conseguinte, na memorización do afecto no lugar, isto é, no proceso de incorporación do afecto ao espazo converténdoo, así, nun lugar atravesado por resonancias emocionais e experienciais.

Nesta liña, a figura do filósofo francés Henri Lefebvre foi central, no eido dos estudos xeográficos, dada a contribución que supuxo o seu recoñecido libro La producción del espacio (2013). Os seus textos permitiron a fundación dunha teoría xeográfica do corpo así como da concepción do corpo social como algo creativo con capacidades xenerativas e que non pode ser reducido a unha condición abstracta, senón que forma parte das prácticas sociais (Simonsen, 2005). En diálogo cos traballos de filósofos como Karl Marx, Martin Heidegger ou Friedrich Nietzsche, Lefebvre conceptualiza os corpos dun xeito espacial e temporal, o que lle permite estudar tanto o espazo do corpo, como o corpo no espazo, e revelar neles unha natureza dinámica e creativa. Desta maneira, pretendía crear unha fenomenoloxía da experiencia vivida situada no espazo entre a mente e o corpo ou, pola contra, entre o suxeito e o obxecto, entendéndoo como un espazo intersubxectivo de percepción que é interpretado a modo dun proceso corporal no que o propio corpo actúa cunha dobre función, por unha banda, como vehículo mediador da percepción e, ao mesmo tempo, como obxecto percibido.

De acordo con isto, Hall interesarase polas maneiras nas que o espazo como "mundo exterior" se recrea no "mundo interior" da nosa experiencia subxectiva centrándose, polo tanto, na cuestión da percepción e afirmando que o espazo, en si mesmo, e a súa percepción non poden ser entendidos 
de maneira separada ou individual. O termo percepción provén do latín percipio, é dicir, do prefixo per-, por completo, e mais do verbo capio, que refire o acto de agarrar ou de tomar entre as mans, relacionándoo así de maneira directa coa cuestión do contacto. É por esta razón que o verbo percibir pode ser interpretado como a acción de ser tocado a través dos sentidos - pola luz, o son, o olor- para despois comprender dun xeito holístico a información dese espazo dende o plano cognitivo. Semella relevante destacar, en sintonía con esta idea, a segunda e a terceira definición que o Diccionario de la lengua española achega para este verbo: "Captar por uno de los sentidos las imágenes, impresiones o sensaciones externas" e "Comprender o conocer algo".

Neste sentido, entendemos que a percepción é artellada por medio da interacción corporal entre o "mundo exterior" e o noso "mundo interior" no que este se procesa. O espazo é, polo tanto, incorporado e internalizado a través da percepción, unha percepción que pode ser potenciada cando adquirimos consciencia dela, xa que é esa consciencia a que nos concede a capacidade de ollar ou de captar o mundo dunha maneira máis completa e profunda. Lupe Gómez introduce na súa poesía este proceso dirixíndoo cara a unha visión ou imaxe máis fonda, traendo así os ollos da aldea até o centro da palabra poética coñecedora da profundidade da súa consciencia sobre o seu mundo. Deste modo, os seus poemas amosan unha apertura na ollada ao xeito de entrada cara a un mundo agochado:

\author{
Os ollos do pai, abertos á Natureza \\ á conciencia limpa, \\ ás vacas íntimas, \\ á inocencia da chuvia, \\ á pureza das emocións, \\ á luz sagrada do viño, \\ á misericordia das sensacións, \\ á poesía escondida no hórreo, \\ á memoria milagrosa. (Gómez, 2017, p. 30)
}

A centralidade da cuestión corporal á hora de achegarnos aos procesos de percepción e interiorización do espazo fora anteriormente apuntada polo filósofo irlandés George Berkeley (2005), quen sentenciara no século XVIII a imposibilidade de pensar o espazo e o ambiente sen ter en conta o corpo. O espazo percibido revélase, deste xeito, como unha elabora- 
ción multisensorial, é dicir, percibida por medio de diferentes estímulos sensoriais externos captados polos cinco sentidos e, ademais, modificada polo factor sociocultural. Este espazo móstrase, en consecuencia, esencialmente ficcional, razón pola que James Gibson (1986) instaurará, dende o campo da psicoloxía, o termo ambiente.

Seguindo esta liña, o antropólogo dos sentidos David Howes (2005) propón o concepto de localización ou emplacement como definición da maneira de artellar a relación sensorial entre o corpo, a mente e o espazo que dá lugar ao ambiente, un ambiente que é tan físico como social. É por este motivo que defende a idea de que a percepción sensorial, dependente do corpo, espazo e mente, é sempre un fenómeno social dado no contexto particular dunha comunidade e, polo tanto, localizado no espazo e no tempo, tal e como estudará posteriormente a socioloxía de Pierre Bourdieu (von Hartenthal e Ono, 2011, p. 7).

Edward T. Hall analiza estas relacións e interaccións poñendo o foco no feito de que a experiencia espacial non é simplemente visual senón tamén multisensorial, o que supón, a partir dese momento, un maior interese cara aos canais auditivo, olfativo e táctil co fin de comprender a percepción do espazo dun xeito completo. Como podemos comprobar no exemplo citado a continuación, a poeta galega atende esas canles a través dos versos do seu poemario, achegando, ao mesmo tempo, un cadro global do mundo que ela lembra e presenta: "Dábame noxo o leite de muxir. Cheiraba mal. Non me gustaba a tona” (Gómez, 2017, p. 44).

Por outra banda, Hall sinala ademais o feito de que estes canais son continuamente transformados polo contexto sociocultural no que se inscribe cada individuo, formándose, entón, a percepción por medio dunha interacción na que toman parte os sentidos, a cultura, a racionalidade e as emocións. Se partimos, polo tanto, da idea de que o corpo é unha entidade en igual medida construída de maneira sociocultural, podemos afirmar que esa cultura ou ese contexto determinado pode ter, en consecuencia, unha axencia transformadora sobre a propia experiencia espacial.

Xa dende os anos 70, Lefebvre (2013) destacaba a necesidade de interpretar e de comprender o espazo dende unha perspectiva que atendese as relacións entre o que el denominou espazo "real", entendido como físico 
ou corporal, e o chamado espazo "ideal", nun sentido abstracto e semellante ao concepto de ambiente de Gibson (1986). O espazo real sería, pois, o "vivido", xerado mediante a experiencia espacial a través dos sentidos. Isto implica analizar de que maneira ten lugar a interacción entre o ser humano e o ambiente do seu redor, é dicir, de que maneira percibimos e interiorizamos o espazo exterior partindo da idea de que este non pode ser captado como algo puro e libre de mediación -no sentido marxista da palabra.

Este pensamento apunta, en certo sentido, cara á estética de Kant (von Hartenthal e Ono, 2011, p. 4), en concreto, cara á súa primacía do suxeito, interpretada como a imposibilidade de aprehender as cousas en si mesmas, pois, segundo este, todo está atravesado pola nosa subxectividade, antepoñendo, ante todo, a sensibilidade e a vivencia do propio suxeito. $\mathrm{O}$ filósofo prioriza, deste xeito, a experiencia corporal como base da percepción espacial, definida non só a través do elemento sensorial, senón tamén da dimensión afectiva e de fenómenos ligados ao pensamento, como a memoria.

\section{A cuestión da memoria e a casa familiar}

Lupe Gómez dá conta da centralidade da memoria e mais do mundo afectivo amosando os espazos nos que se sitúan os poemas dende unha perspectiva anovada. Son diversos os espazos que podemos atopar entre os versos de Camuflaxe, pois a autora realiza un percorrido tanto polos privados coma polos públicos coa intención de traer ante os lectores unha imaxe que inclúa a totalidade da realidade vivida na aldea galega. A pesar disto, entre todos eles destacará o elemento da casa como un símbolo que resoa en todos os espazos nomeados pois, tal e como apuntou Gaston Bachelard (2000, pp. 35-37), todo espazo habitado leva como esencia a noción da casa.

No seu libro La poética del espacio, este filósofo francés achéganos a súa fenomenoloxía da imaxinación por medio de espazos e obxectos sinxelos, mais que ostentan unha enorme carga afectiva; entre eles enfatizará especialmente a imaxe poética da casa. Segundo Bachelard, esta é un elemento de integración psicolóxica que garda en si mesma a lembranza e o esquecemento e, por esta razón, está directamente ligada aos procesos de remi- 
niscencia. En consecuencia, a casa aparece no poemario coma símbolo ou emblema da infancia e da orixe e, polo tanto, como un principio unificador dos pensamentos, lembranzas e soños dunha persoa, situándose, así, nun espazo fronteirizo no que se produce un cruce temporal entre o pasado, o presente e o futuro.

O discurso poético da imaxe da casa maniféstase a un tempo violento e fráxil así como en estreita relación coa cotiandade, presentando, pola contra, un microcosmos de seu. Dende o interior da casa, a poeta consegue outorgarlles ás cousas que coñecía unha significación nova derivada da profundidade da súa anovada ollada sobre elas; unha que, non obstante, non esquece a presenza dos muros desa casa. Deste modo, a voz poética presenta un proceso de aprendizaxe acerca dun coñecemento camuflado ou dunha "enerxía secreta", en palabras dela, propia deste espazo marxinal. Como podemos comprobar nos seus versos, esta aprendizaxe e comprensión do espazo faise posible grazas ao xiro mencionado cara a unha ollada profunda e atravesada pola cuestión afectiva: "Aprendo a escoitar as nubes, a traballar a terra e a ler o ceo, / no teu colo" (Gómez, 2017, p. 19).

Neste sentido, a voz repara nas accións e cousas propias do mundo privado da intimidade que a priori non son consideradas literarias co fin de dignificalas por medio da palabra poética. Así, a autora representa e escribe sobre actos tan cotiáns como lavar as mans e a roupa ou facer pan, así como outros tan íntimos como vomitar ou parir, este último, cunha presenza especialmente recorrente. Lupe Gómez presenta a súa volta á casa familiar e ás lembranzas da súa infancia para escribir sobre o seu propio descubrimento do mundo dende a intimidade do fogar, especialmente, a través da relación íntima coa súa nai: "Eu mirábate e descubría a beleza da intimidade" (Gómez, 2017, p. 38). Percorre, deste xeito, cada estancia e recuncho da casa para escribir dende os espazos onde non entrara antes a palabra poética, como a cociña, o faiado, a lareira ou o cuarto, preocupándose, ademais, por dar conta dos rituais e dos ritmos propios deste lugar coa importancia que se lle dá ao sagrado. En definitiva, a voz poética debuxa todas estas accións e imaxes coa intención de configurar os símbolos que constrúen, a través da palabra, este espazo aínda non esquecido.

Segundo a teoría de Bachelard, o elemento da casa preséntase sempre cun valor ou poder de protección contra as forzas que o asaltan, cons- 
tituíndose, polo tanto, coma un refuxio para os que habitan nela. Desta maneira, a casa oponse, en certo modo, ao mundo exterior, intensificando, en consecuencia, valores íntimos coma os que atopamos nos poemas de Camuflaxe. Por outra banda, as casas do pasado poden aparecer ante nós como espazos fráxiles e vulnerábeis mais, a pesar disto, actuar como niños, isto é, proporcionándonos unha ilusión de seguridade que opera a través dun instinto revivido. Este niño do que nos fala Bachelard aparece nos versos da poeta galega en relación directa, ademais, coa figura a un tempo fráxil e protectora da nai nunha unión natural: "Nai camuflada. Niño de paxaros" (Gómez, 2017, p. 18).

A casa constitúese, deste modo, como o noso propio punto de referencia no mundo, representando, en consecuencia, o habitar e mais a protección aínda sendo unha ilusión dela. Isto é, a casa familiar actúa como un punto de encontro entre a memoria e a imaxinación que, ao ser invocada pola voz poética do presente, consegue que o pasado permaneza vivo dalgún xeito. A fin de representar este espazo, Lupe Gómez sérvese das lembranzas familiares para recoller as experiencias pasadas que aparecen conxugadas co espazo percibido no presente dende o que escribe. No proceso de escritura créase, por esta razón, un diálogo materno-filial que lle axuda a construír este espazo da experiencia por medio da memoria.

Noutra liña, aínda que o centro de atención se sitúa na casa familiar, a voz poética percorre outros lugares da aldea co obxectivo de recoller, así mesmo, as palabras e as lembranzas da xente que a habita, realizando, así, un exercicio de rememoración e de memoria colectiva emprazado neste espazo en decadencia. A poeta demostra, deste xeito, a importancia do papel da comunidade no marco dos espazos marxinais como son as aldeas rurais, dándolles voz e dignidade non só aos testemuños da xente, senón tamén incluíndo aqueles espazos públicos que ocupan unha función central na aldea, pois operan como lugares de reunión para a comunidade; estes son a igrexa, a feira ou a festa.

En correspondencia con isto, a autora denota unha preocupación especial por describir os espazos en relación cos seus habitantes, é dicir, por revelar a dialéctica afectiva que opera entre ambos para amosar de que maneira inciden uns nos outros. Neste sentido, a poética de Lupe Gómez está suxeita a unha ética dos afectos interpersoais pois, tal e como apunta 
Rábade Villar (2019): "la autora tensa como pocos escritores la capacidad relacional de los afectos, al usarlos para llamar la atención sobre los vínculos interpersonales, en el sentido comunitario y en el más estrictamente familiar [...] pero también los vínculos entre el ser humano y la naturaleza”.

\section{Un diálogo coa voz materna}

De acordo coa teoría mencionada de Bachelard, a casa significa o ser interior (2000, p. 18) mais, ao igual que foi apuntado previamente, esta tamén pode ser un símbolo feminino asociado á nai, ao refuxio e á protección do seo maternal (Bachelard, 2000, p. 14), polo que se establece un fío de unión esencial entre a casa, a nai e a voz poética: "O parto foi na cociña dunha casa con chan de terra" (Gómez, 2017, p. 14). Por esta razón, a casa ecoa unha serie de imaxes de intimidade protexida que multiplican os valores da realidade por medio da imaxinación. En consecuencia, a memoria e a imaxinación son indisociábeis aquí á hora de construír a imaxe da casa, pois a voz poética establece un diálogo ficticio coa nai amosando un fío de unión indestrutíbel entre elas que vai para alén do seu falecemento, xa que practicamente consegue fundilas nun mesmo corpo: "O meu sangue era un lazo co teu ventre avultado" (Gómez, 2017, p. 14), "Sentir que existes en min e existo en ti...” (Gómez, 2017, p. 75).

Este diálogo materno-filial será, polo tanto, tamén un diálogo constante coa morte, posto que, tal como apuntou Arturo Casas no seu "Glosario para lupenautas" (2013, p. 167), a morte para ela "dista de ser un rito de paso, trataríase máis ben dun estado necesario para a intervención social e política. Dunha disposición, mesmo". Nesta liña, no caso concreto de Camuflaxe podemos ler: "Gústame máis / escribir cartas para persoas mortas que para persoas vivas. Os mortos escoitades mellor. As nais nunca morredes" (Gómez, 2017, p. 89).

Desta maneira, o papel da nai, como clásica alegoría da natureza ou da patria, actualízase nos seus textos en tanto que suxeito vivo, activo e participativo do eu poético así como do espazo a construír. Esta relación entre as mulleres e o mundo natural foi apuntada pola, relativamente nova, corrente do denominado ecofeminismo a través desa nova perspectiva. No sentido no que o expoñen Greta Gaard e Patrick Murphy no seu libro 
Ecofeminist Literary Criticism: Theory, Interpretation, Pedagogy (1998), o ecofeminismo pode definirse como un movemento social anti-xerárquico que foi capaz de ligar os procesos de dominación hetero-patriarcal coa dominación exercida sobre a natureza en todo o seu conxunto, así como sobre os habitantes e os modos de vida propios das zonas máis rurais ligadas á dita natureza.

Por conseguinte, do mesmo xeito que o territorio, a nai pasará de ser a figura pasiva tradicional da paisaxe ollada, a ser propiamente a paisaxe axente que mira, pois así o explica a poeta: "Unha nai é unha cartografia inventada que ninguén nos pode roubar / un periódico que publica cada día exclusivas" (Gómez, 2017, p. 85). Esa nai agora morta, cartografía inventada, desvía e desartella a proxección do eu poético tradicional. É nesta distancia ou no escoitar, en palabras do filósofo Michel de Certeau en La invención de lo cotidiano (2000, p. 122), onde xorde a posibilidade real de crítica para a poeta: "La diferenciación del cuerpo respecto de la madre en el hijo. Allí se inaugura la posibilidad de un espacio y de una localización (un 'no todo') del sujeto".

\section{Conclusión}

En definitiva, Lupe Gómez debuxa no seu poemario unha imaxe tanto completa como complexa dun mundo galego en decadencia que aínda semella cruzado por lazos afectivos fondos e fortes. Por medio dos diferentes espazos públicos e privados, que conforman o seu mapa poético, e dos símbolos que ocupan unha posición central na súa experiencia vital, como son a casa familiar e a nai, a autora dá conta dunha vida e duns valores propios deste lugar grazas á súa capacidade para atopar a voz das nais camufladas "nos sublimes restos da paisaxe" (Gómez, 2017, p. 30).

Finalmente, Gómez escribe, a partir da memoria individual e colectiva así como da imaxinación, sobre as ruínas do seu mundo co fin de asegurarlles un lugar no futuro, demostrando así unha consciencia plena de que o obstáculo máis insalvabel non é a morte senón o esquecemento. Camuflaxe artéllase, desta maneira, como unha carta a un tempo cara ó pasado e cara ó futuro, como un lugar de resistencia e un acto de piedade que sanda un mundo perdido na súa vontade por "Recoller, recordar e gardar os fragmentos rotos” (Gómez, 2017, p. 69). 


\section{Referencias bibliográficas}

Bachelard, G. [1957] (2000). La poética del espacio. Fondo de Cultura Económica de Argentina.

Berkeley, G. (2005). A treatise concerning the principles of human knowledge. En G. Berkeley, The works of George Berkeley, vol. 1 (pp. 69-147). Elibron Classics.

Casas, A. (2013). Glosario para lupenautas. En B. Baltrusch (Ed.), Lupe Gómez: libre e estranxeira. Estudos e traducións (pp. 159-179). Frank \& Timme.

Casey, E. S. [1987] (2000). Remembering. A Phenomenological Study. Indiana University Press.

Gaard, G. e Murphy, P. (1998). Ecofeminist Literary Criticism: Theory, Interpretation, Pedagogy. University of Illinois Press.

Gibson, J.J. [1979] (1986). The ecological approach to visual perception. Hillsdale.

Gramsci, A. [1975] (1981-2000). Cuadernos de la cárcel, 6 vols. ERA e Universidad de Puebla.

Gómez, L. (2005). O útero dos cabalos. Espiral Maior.

Gómez, L. (2017). Camuflaxe. Chan da Pólvora.

Hall, E. T. [1966] (1993). La dimensión oculta. Siglo Veintiuno.

Heft, H. e Nazar, J. L. (2000). Evaluating Environmental Scenes Using Dynamic versus Static Displays. Environment and Behavior, 32, 301-322.

Howes, D. (2005). The empire of the senses: the sensual culture reader. Bergs Publishers.

Labrador Méndez, G. (2016). Las Églogas de la Acumulación Originaria. Paisajización, desposesión y memoria demo-poética desde Cantares Gallegos (1863) de Rosalía de Castro. En K. Soriano Salkjelsvik e F. Martínez Pinzón (Ed.), Revisitar el costumbrismo. Cosmopolitismo, pedagogías y modernización en Iberoamérica. Peter Lang.

Lefebvre, H. [1974] (2013). La producción del espacio. Capitán Swing.

López, M. (2008). Paisaxe e nación: a creación discursiva do territorio. Galaxia. 
López, M. (2012). Memoria, ecoloxía e identidade na Galiza. En G. Sanmartín Rei (Ed.), Lingua e ecoloxía: VIII Xornadas sobre Lingua e usos (pp. 51-64). Universidade da Coruña.

Massumi, B. (2002). Parables for the Virtual: Movement, Affect, Sensation. Duke University Press.

Nogueira, M. X. (2011). Identidade nación e compromiso na poesía galega do novo século. En M. X. Lama e M. X. Nogueira (Cords.), Poesía galega. Perspectivas criticas e comparadas. Boletín Galego de Literatura, 45, 107-120. https://cutt. ly/jhk2xsT

Nora, P. (1992). Les Lieux de Mémoire: La République, La Nation, Les France, 3 vols. Gallimard.

Pato, C. (2000). m-talá. Edicións Xerais de Galicia.

Rábade Villar, M. d. C. (2010). The concept of resistance in contemporary Galician culture: towards a poetic ecology. Cosmos and history: The fournal of Natural and Social Philosophy, 6 (2), 82-92. https://cutt.ly/Ihk2fdZ

Rábade Villar, M. d. C. (2019). De afectos y desafectos. La representación del mundo rural en la poesía gallega contemporánea. En R. Spiller, A. Calderón Puerta e K. Moszcyzinska Dürst (Eds.), Extremas. Figuras de la felicidad y la furia en la producción cultural ibérica y latinoamericana del siglo XXI. Peter Lang.

Rosenwein, B. H. (2006). Emotional Communities in the Early Middle Ages. Cornell University Press.

Simonsen, K. (2005). Bodies, Sensations, Space and Time: The Contribution from Henri Lefebvre. Geografiska Annaler. Series B, Human Geography, 87 (1), $1-14$.

Spinoza, B. [1677] (2001). Ethics. Wordsworth Editions.

Tuan, Y-F. (1997). Space and Place: The perspective of Experience. University of Minnesota Press.

Von Hartenthal, M. e Mitsuko Ono, M. (2011). O espaço percibido: em busca de uma definição conceitual. Arquitecturarevista, 7 (1), 2-8.

VVAA. Diccionario de la Real Academia Española. [en liña]. https://dle.rae.es/

Williams, R. (1977). Marxism and Literature. Oxford University Press.

Williams, R. (2001). El campo y la ciudad. Paidós. 